\title{
Highly enantioselective synthesis of $(R)$-1,3-butanediol via deracemization of the corresponding racemate by a whole-cell stereoinverting cascade system
}

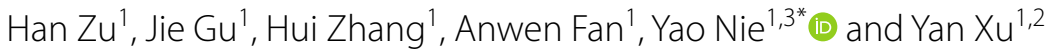

\begin{abstract}
Background: Deracemization, the transformation of the racemate into a single stereoisomeric product in 100\% theoretical yield, is an appealing but challenging option for the asymmetric synthesis of optically pure chiral compounds as important pharmaceutical intermediates. To enhance the synthesis of (R)-1,3-butanediol from the corresponding low-cost racemate with minimal substrate waste, we designed a stereoinverting cascade deracemization route and constructed the cascade reaction for the total conversion of racemic 1,3-butanediol into its ( $R$ )-enantiomer. This cascade reaction consisted of the absolutely enantioselective oxidation of (S)-1,3-butanediol by Candida parapsilosis QC-76 and the subsequent asymmetric reduction of the intermediate 4-hydroxy-2-butanone to (R)-1,3-butanediol by Pichia kudriavzevii QC-1.
\end{abstract}

Results: The key reaction conditions including choice of cosubstrate, $\mathrm{pH}$, temperature, and rotation speed were optimized systematically and determined as follows: adding acetone as the cosubstrate at $\mathrm{pH} 8.0$, a temperature of $30^{\circ} \mathrm{C}$, and rotation speed of $250 \mathrm{rpm}$ for the first oxidation process; in the next reduction process, the optimal conditions were: adding glucose as the cosubstrate at pH 8.0, a temperature of $35^{\circ} \mathrm{C}$, and rotation speed of $200 \mathrm{rpm}$. By investigating the feasibility of the step-by-step method with one-pot experiment as a natural extension for performing the oxidation-reduction cascade, the step-by-step approach exhibited high efficiency for this cascade process from racemate to (R)-1,3-butanediol. Under optimal conditions, $20 \mathrm{~g} / \mathrm{L}$ of the racemate transformed into $16.67 \mathrm{~g} / \mathrm{L}$ of $(R)$ 1,3-butanediol with $99.5 \%$ enantiomeric excess by the oxidation-reduction cascade system in a 200-mL bioreactor.

Conclusions: The step-by-step cascade reaction efficiently produced (R)-1,3-butanediol from the racemate by biosynthesis and shows promising application prospects.

Keywords: Stereoselectivity, (R)-1,3-butanediol, Racemate, Whole-cell catalysis, Oxidation-reduction cascade

\section{Background}

Chiral alcohols are widely used in the fields of medicine, food, chemicals, and pesticides due to their unique optical activity [1-3]. (R)-1,3-butanediol ((R)-1,3-BDO) is an

\footnotetext{
${ }^{*}$ Correspondence: ynie@jiangnan.edu.cn

1 Key Laboratory of Industrial Biotechnology, Ministry of Education,

School of Biotechnology, Jiangnan University, 1800 Lihu Road, Wuxi 214122, China

Full list of author information is available at the end of the article
}

important chiral alcohol used for the synthesis of pheromones, fragrances, and insecticides [4-6]. (R)-1,3-BDO is also a critical pharmaceutical intermediate, especially as a precursor for the synthesis of azetidinone derivatives, which in turn are key chiral intermediates for the synthesis of penem and carbapenem $\beta$-lactam antibiotics [7]. The demand for $(R)-1,3-\mathrm{BDO}$ has drastically increased as $\beta$-lactam antibiotics are the most used antibacterial

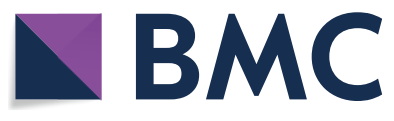

(c) The Author(s) 2020. This article is licensed under a Creative Commons Attribution 4.0 International License, which permits use, sharing, adaptation, distribution and reproduction in any medium or format, as long as you give appropriate credit to the original author(s) and the source, provide a link to the Creative Commons licence, and indicate if changes were made. The images or other third party material in this article are included in the article's Creative Commons licence, unless indicated otherwise in a credit line to the material. If material is not included in the article's Creative Commons licence and your intended use is not permitted by statutory regulation or exceeds the permitted use, you will need to obtain permission directly from the copyright holder. To view a copy of this licence, visit http://creativecommons.org/licenses/by/4.0/. The Creative Commons Public Domain Dedication waiver (http://creativecommons.org/publicdomain/zero/1.0/) applies to the data made available in this article, unless otherwise stated in a credit line to the data. 
agents in clinical practice worldwide; its production method has consequently been extensively studied $[8,9]$.

Currently, $(R)-1,3-\mathrm{BDO}$ is produced by chemical synthesis or microbial conversion. Regarding the chemical process, Boaz et al. [5] observed that ruthenium complexes of phosphine-aminophosphine produced $(R)$ $1,3-\mathrm{BDO}$ by the asymmetric reduction of its prochiral precursor 4-hydroxy-2-butanone (4H2B) with $81.8 \%$ enantiomeric excess (ee); Yasuo et al. [6] obtained 3-hydroxybutanal by acetaldehyde condensation, which was then hydrogenated to become $(R)-1,3-\mathrm{BDO}$ with the Raney Ni catalyst. However, the product obtained by the chemical route has a low optical purity, and preparation of the chemical catalyst is difficult and expensive. In addition, some dangerous reagents are usually necessary for chemical synthesis, and the reaction conditions are severe [10-12]. In contrast, the biocatalytic process presents the advantages of requiring mild reaction conditions, providing a high stereoselectivity, producing few by-products, and leaving no residual metals in the product $[4,11,12]$. Matsuyama et al. [13] isolated Candida arborea IAM 4147 and Issatchenkia scutalata IFO 10070 from soil samples and completed the conversion from $4 \mathrm{H} 2 \mathrm{~B}$ to $(R)-1,3-\mathrm{BDO}$, with yields of only $37 \%$ and $48 \%$; Zheng et al. [9] used C. krusei ZJB-09162 to transform $45 \mathrm{~g} / \mathrm{L}$ of $4 \mathrm{H} 2 \mathrm{~B}$ into $(R)-1,3-\mathrm{BDO}$ through a fed-batch fermentation with $99 \% e e$, and a yield of $83.9 \%$. However, $4 \mathrm{H} 2 \mathrm{~B}$ is an expensive intermediate and is therefore unsuitable for large-scale industrial production. In order to solve this problem, Kataoka et al. [14] constructed a synthetic pathway by genetic engineering in Escherichia coli MG1655 laclq to produce (R)-1,3-BDO from glucose: this process reached an optical purity of $98.5 \%$ $e e$ and a 1,3-BDO concentration of only $9.05 \mathrm{~g} / \mathrm{L}$. Matsuyama et al. [15] also tried to complete the conversion from racemate to $(R)-1,3-\mathrm{BDO}$ using $C$. parapsilosis IFO 1396 , achieving a $50 \%$ yield with $95 \% e e$. The $(S)-1,3-\mathrm{BDO}$ in the racemate was dehydrogenated, while the $(R)-1,3-$ BDO was preserved, which meant that the maximum yield of $(R)-1,3-\mathrm{BDO}$ was theoretically limited to $50 \%$.

Although kinetic resolution is the most accessible method to obtain the enantiomerically pure alcohol from its racemate, through this process the maximum yield of the desired enantiomer is limited to $50 \%$ [16]. To overcome this drawback, a stereoinversion-based oxidationreduction cascade is applied to the synthesis of chiral alcohols, reducing the waste of raw materials and energy, increasing the overall reaction yield, and reducing the time-consuming step of isolation of intermediates [1719]. However, challenges involved in this process include screening absolutely stereospecific catalysts for selective oxidation and asymmetric reduction, respectively, connecting the oxidation and reduction steps synergistically without the need for isolating the intermediates, as well as controlling different reaction conditions between the oxidation and reduction steps [20,21]. It is therefore critical to select two biocatalysts with opposite enantioselectivity for the oxidation-reduction stereoinversion and reduce the mutual influences in the cascade by optimizing reaction conditions $[11,22]$.

In this work, we obtained C. parapsilosis QC-76 and Pichia kudriavzevii QC-1 with absolute stereoselectivity by screening more than 500 isolated strains from soil samples. Using two stereoselective strains, we aimed to develop an enantioselective cascade biocatalysis for the deracemization of racemic $(R, S)-1,3-\mathrm{BDO}$ to $(R)$ 1,3-BDO (Fig. 1). C. parapsilosis QC-76 catalyzed the stereoselective oxidation and P. kudriavzevii QC-1 catalyzed the next asymmetric reduction, forming the whole cascade deracemization process. The two steps were conducted sequentially, producing optically pure $(R)$ 1,3-BDO after the optimization of reaction conditions, including cosubstrate, $\mathrm{pH}$, temperature, and rotation speed.

\section{Results}

\section{Screening of microorganisms}

544 colonies were screened from soil samples for the two-step reaction. For the first oxidation step, racemate was chosen as the substrate, and we calculated the yield and the $e e$ of $(R)-1,3$-BDO produced by the tested strains. As shown in Fig. 2a, most of the strains achieved a low ee (-30 to $30 \%)$ and showed low specificity to racemate. In comparison, strain QC-76 was able to oxidize $(S)$ 1,3-BDO into $4 \mathrm{H} 2 \mathrm{~B}$ and stereospecifically conserve the $(R)-1,3-\mathrm{BDO}$ in the racemate, providing $99.74 \%$ ee and a $49.39 \%$ yield. Strain QC-76 was therefore chosen for the oxidation step. Considering the reduction step, 4H2B was chosen as the substrate, and yields of $(R)-1,3-\mathrm{BDO}$ and its $e e$ were compared. As shown in Fig. 2b, strain QC-1 provided yield and $e e$ of $(R)-1,3-\mathrm{BDO}$ of $98.89 \%$ and $99.83 \%$, respectively, and thus was chosen for the second step. These two strains, QC-76 and QC-1, would be used to construct a two-step reaction system for converting racemate into $(R)-1,3-\mathrm{BDO}$.

\section{Strain identification}

The morphologies of QC-76 and QC-1 were observed by field emission scanning electron microscope and both were preliminarily determined as yeast. Both strains presented elliptical and elongated cells, with buddings occurring at multiple sites (Fig. 2c, d).

To further identify the screened strains, we performed a $5.8 \mathrm{~S}$ internal transcribed spacer (ITS) analysis. The 5.8S-ITS sequences of strains QC-76 and QC-1 were analyzed, and two phylogenetic trees were constructed. 

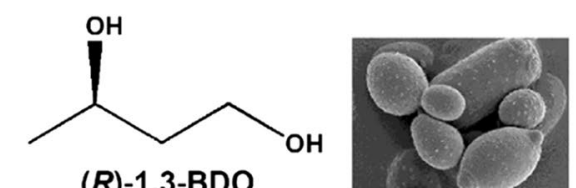

(R)-1,3-BDO

Candida parapsilosis QC-76

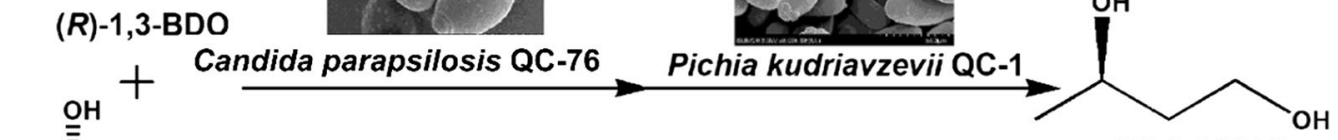<smiles>C[C@H](O)CCO</smiles>

(S)-1,3-BDO

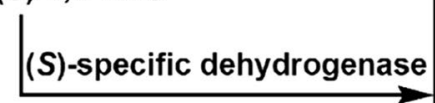<smiles>CC[C@@H](O)CCO</smiles>

(R)-1,3-BDO

(R)-1,3-BDO

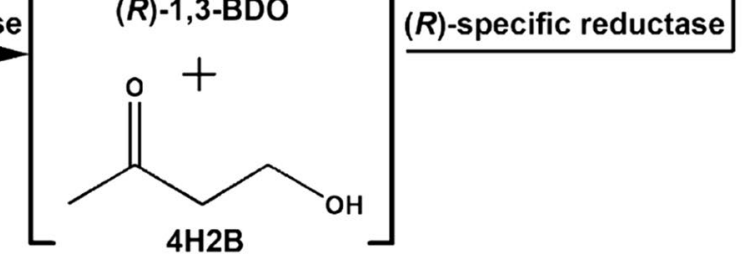

$(R)$-specific reductase

Fig. 1 Schematic representation of the cascade oxidation-reduction system for $(R)-1,3-B D O$ production from its racemate

Sequences were deposited in GenBank under the accession numbers MN545611.1 and MK894151.1. As shown in Fig. 2e, f, strain QC-76 was closely clustered with $C$. parapsilosis NRRL Y-12969 (GenBank accession no. FJ153210.1), with a sequence identity of 98\%; strain QC-1 was closely clustered with $P$. kudriavzevii CBS 5147 (GenBank accession no. CP028532.1), with a sequence identity of $100 \%$. Based on the results of the phylogenetic analysis and phenotypic tests, the isolates were designated as C. parapsilosis QC-76 and P. kudriavzevii QC-1.

\section{Catalytic specificity of the identified strains}

In this work, to facilitate the whole cells-mediated oxidoreductions, different cosubstrates commonly used for cofactor regeneration were tested. For the oxidation step (Fig. 3a), when acetone was chosen as cosubstrate, the $4 \mathrm{H} 2 \mathrm{~B}$ yield reached $46.53 \%$ with $97.22 \%$ ee; regarding the reduction step (Fig. $3 \mathrm{~b}$ ), glucose as a cosubstrate resulted in a $(R)-1,3-\mathrm{BDO}$ yield of $80.3 \%$, with $99.4 \%$ ee. Therefore, acetone and glucose were selected as the cosubstrates for the oxidation and reduction reactions, respectively.

In order to achieve a high optical purity in chiral alcohol production, the oxidation and reduction steps should present high stereoselectivity and yield. Two independent experiments were performed to verify the catalytic specificity of $C$. parapsilosis QC-76 towards (S)-1,3-BDO and of $P$. kudriavzevii QC-1 towards 4H2B. As shown in Fig. 4a, in the step catalyzed by C. parapsilosis QC-76, $10 \mathrm{~g} / \mathrm{L}$ of $(S)-1,3-\mathrm{BDO}$ in the racemate were gradually reduced until almost zero, and the $4 \mathrm{H} 2 \mathrm{~B}$ concentration gradually increased from $0 \mathrm{~g} / \mathrm{L}$ to $9.62 \mathrm{~g} / \mathrm{L}$. Meanwhile, the $(R)-1,3-\mathrm{BDO}$ concentration remained almost unchanged, indicating that (S)-1,3-BDO was dehydronated to $4 \mathrm{H} 2 \mathrm{~B}$ in a stereoselective manner. Figure $4 \mathrm{~b}$ indicates that, in the step catalyzed by $P$. kudriavzevii QC-1, $20.00 \mathrm{~g} / \mathrm{L}$ of $4 \mathrm{H} 2 \mathrm{~B}$ were transformed into $18.64 \mathrm{~g} / \mathrm{L}$ of $(R)-1,3-\mathrm{BDO}$ with a $93.2 \%$ yield, and $(S)-1,3-\mathrm{BDO}$ was not detected. The asymmetric synthesis of $(R)-1,3-\mathrm{BDO}$ from $4 \mathrm{H} 2 \mathrm{~B}$ by $P$. kudriavzevii QC-1 was therefore also stereospecific, producing $(R)-1,3-\mathrm{BDO}$ with over $99 \%$ ee. Therefore, the two necessary steps involved in deracemization of racemic 1,3-BDO were achieved. To understand the compatibility between C. parapsilosis QC-76 catalyzing selective oxidation and P. kudriavzevii QC-1 catalyzing asymmetric reduction, effects of various reaction conditions on each single-step conversion were investigated, which provide the basis for further construction of stereoinverting cascade system.

\section{Effect of cosubstrate concentration on asymmetric oxidation/reduction}

As shown in Fig. $5 \mathrm{a}$, the use of $30 \mathrm{~g} / \mathrm{L}$ acetone resulted in the best yield of $4 \mathrm{H} 2 \mathrm{~B}(45.06 \%)$ in the oxidation step. As the acetone concentration increased to $40 \mathrm{~g} / \mathrm{L}$, the yield decreased to $39.74 \%$. Excess acetone has been reported to have a toxic effect on cells and to affect their catalytic activity [23]. Finally, the optimal mass ratio between acetone and racemate that yielded the most $4 \mathrm{H} 2 \mathrm{~B}$ was $3: 1$ (molar ratio=4.7:1). For the reduction step, the $(R)-1,3-\mathrm{BDO}$ yield was the highest when glucose concentration was $24 \mathrm{~g} / \mathrm{L}$. When glucose concentration was increased above $24 \mathrm{~g} / \mathrm{L}$, the (R)-1,3-BDO yield rapidly decreased. The gluconic acid generated from glucose was probably accumulated, 
a

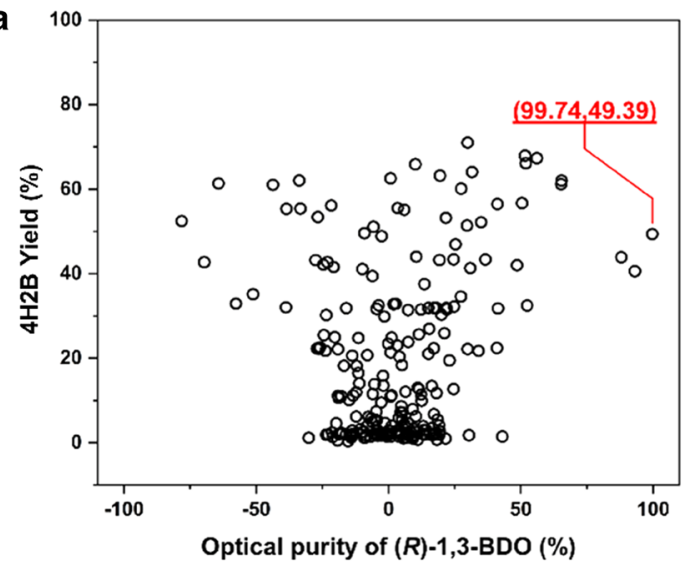

C

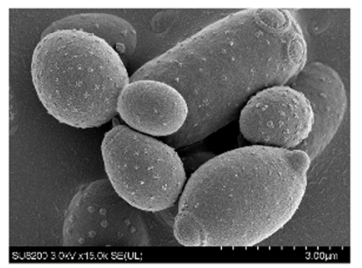

b

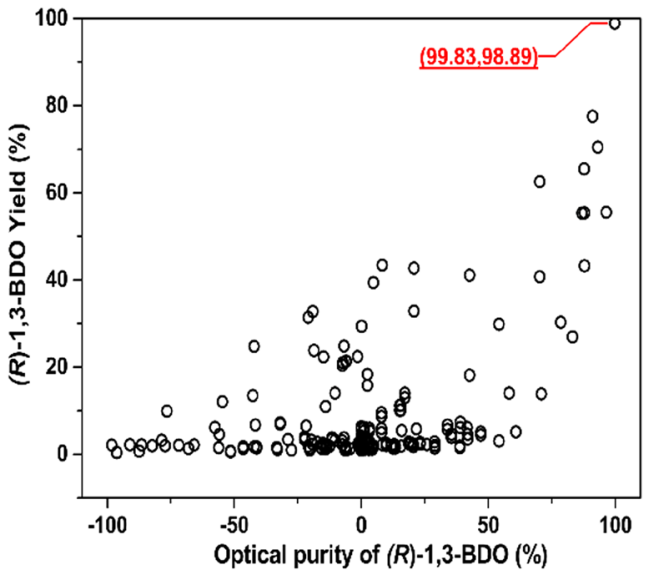

d

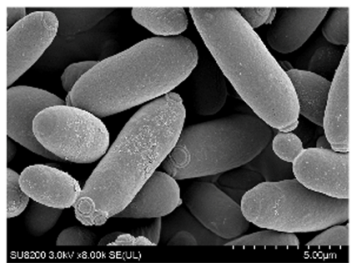

e

98 MN545611.1 Candida parapsilosis QC-76

88 FJ153210.1 Candida parapsilosis NRRL Y-12969

KF313193.1 Candida orthopsilosis ATCC 96139

NR_138276.1 Candida africana CBS 8781

NR_119386.1 Candida dubliniensis CBS 7987

NR_111722.1 Candida theae ATCC MYA-4746

NR 138345.1 Candida viswanathii ATCC 22981

KY102203.1 Candida metapsilosis CBS 10907

$\stackrel{\longmapsto}{0.05}$

f

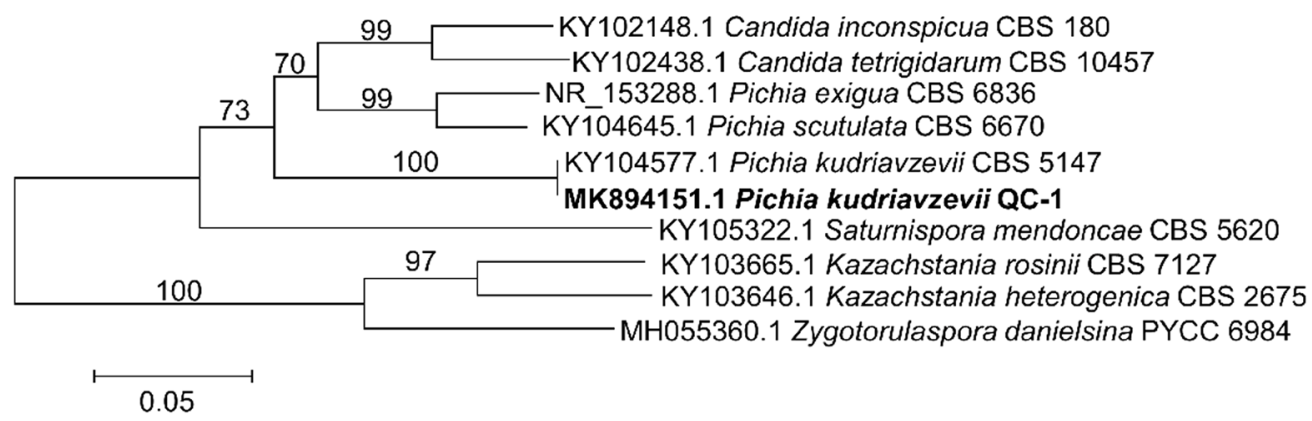

Fig. 2 Functional screening, morphological observations and genes identification of target strains. a Screening of strains that transformed racemate into $4 \mathrm{H} 2 \mathrm{~B} ; \mathbf{b}$ screening of strains that transformed $4 \mathrm{H} 2 \mathrm{~B}$ to $(R)-1,3-\mathrm{BDO} ; \mathbf{c}$ field emission scanning electron microscope of strain QC-76; $\mathbf{d}$ field emission scanning electron microscope of strain QC-1; e phylogenetic tree of strain QC-76 based on 5.8S-ITS rDNA sequences; $\mathbf{f}$ phylogenetic tree of strain QC-1 based on 5.8S-ITS rDNA sequences

leading to a significant drop in $\mathrm{pH}$ that could affect cell survival and conversion efficiency [24]. Finally, the optimal mass ratio between glucose and $4 \mathrm{H} 2 \mathrm{~B}$ was $6: 5$ $($ molar ratio $=1: 1.7)$, and the maximum $(R)-1,3-\mathrm{BDO}$ yield reached $80.3 \%$.
Effect of $\mathrm{pH}$ on asymmetric oxidation/reduction

As illustrated in Fig. 5b, the $\mathrm{pH}$ exerted a significant impact on the oxidation and reduction rates. Both oxidation and reduction steps were improved with a rise in $\mathrm{pH}$ from 4.0 to 8.0. Further increasing reaction $\mathrm{pH}$, 

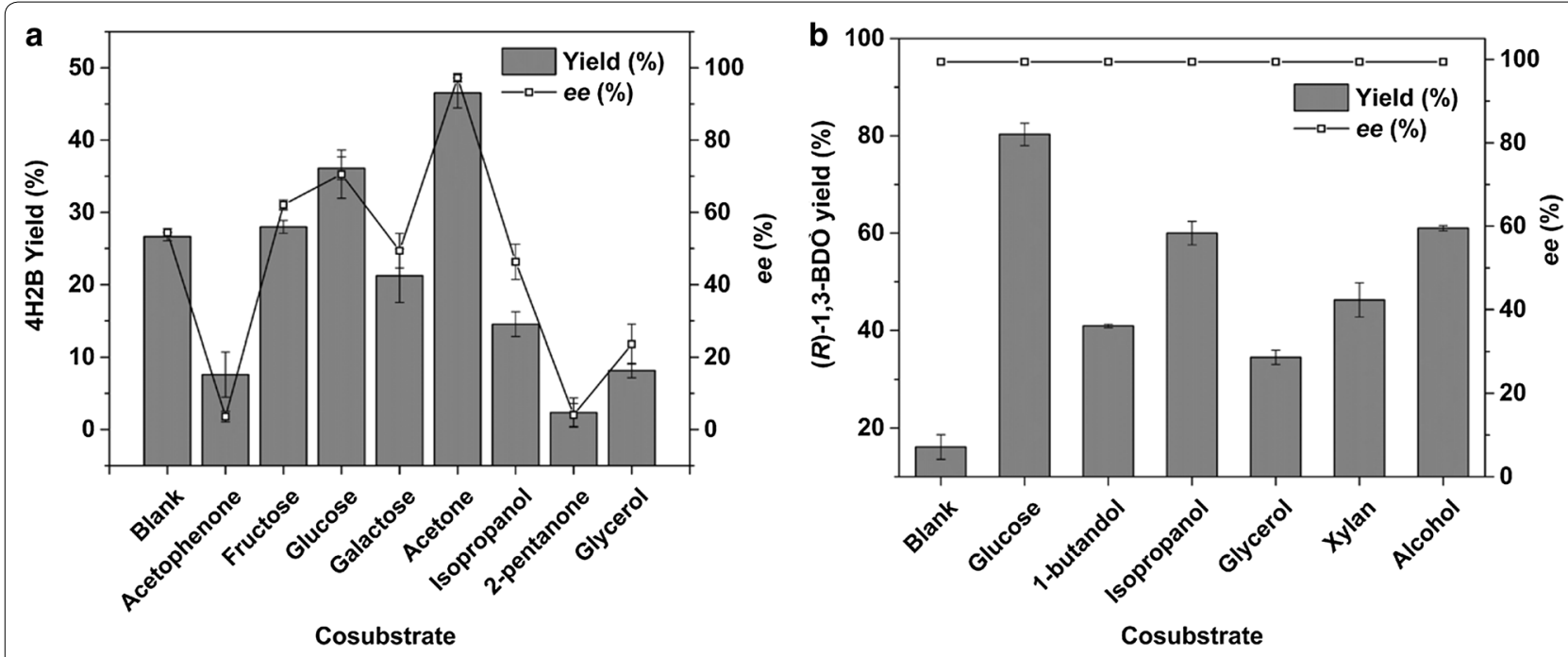

Fig. 3 Effects of cosubstrates on single-step reactions. a Selective oxidation of racemate; $\mathbf{b}$ asymmetric reduction of $4 \mathrm{H} 2 \mathrm{~B}$
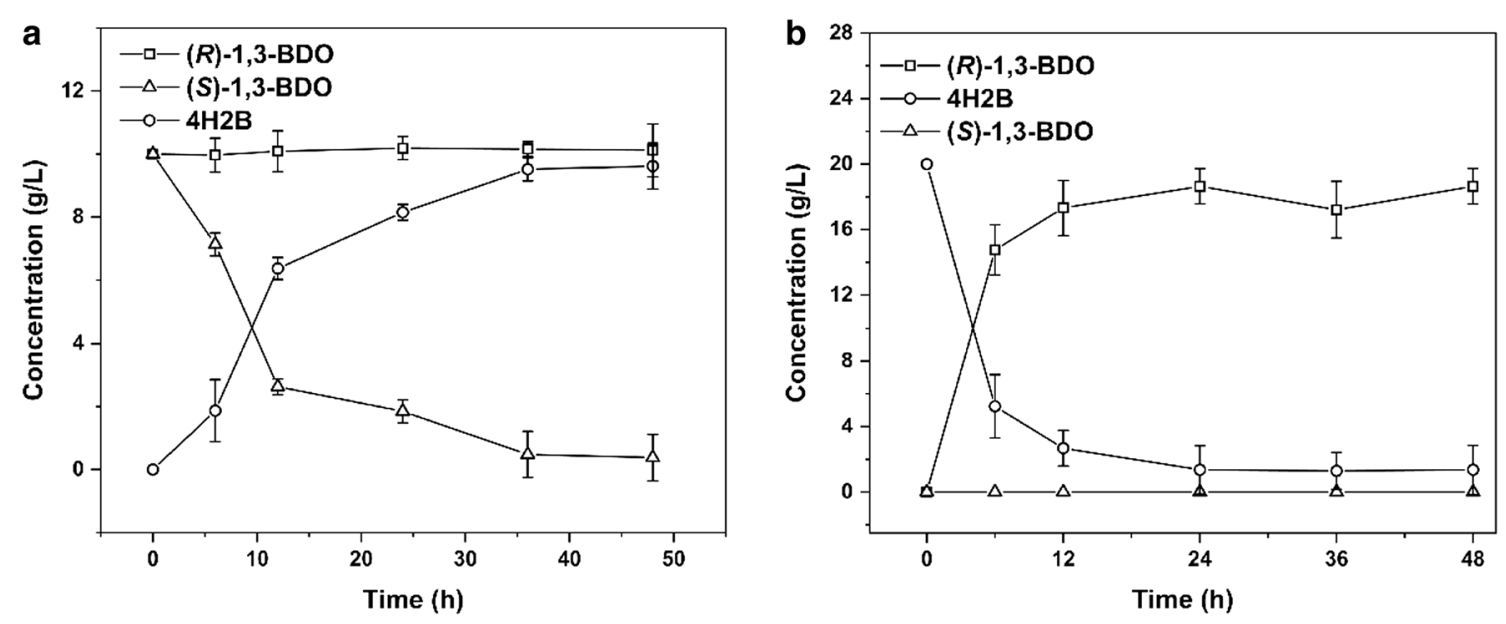

Fig. 4 Time courses of single-step reactions. a Selective oxidation of racemate; $\mathbf{b}$ asymmetric reduction of $4 \mathrm{H} 2 \mathrm{~B}$

however, resulted in lower yields for both reactions. Finally, the optimum $\mathrm{pH}$ for the oxidation and reduction steps was determined to be 8.0, where the yields of the oxidation and reduction steps were $47.10 \%$ and $85.18 \%$, respectively.

\section{Effect of temperature on asymmetric oxidation/reduction}

As shown in Fig. 5c, temperature ranged from 20 to $45{ }^{\circ} \mathrm{C}$, with $5{ }^{\circ} \mathrm{C}$ intervals. When temperature was below $25^{\circ} \mathrm{C}$, yields of the two-step reaction were generally low, indicating low enzyme activity at these temperatures. The optimal temperatures for the oxidation and reduction steps were $30^{\circ} \mathrm{C}$ and $35^{\circ} \mathrm{C}$, respectively. When temperature increased to $45^{\circ} \mathrm{C}$, the yield of the oxidation reaction decreased to $37.52 \%$ and that for the reduction reaction decreased to $43.19 \%$, which could indicate a partial inactivation of the cells' enzymes.

\section{Effect of rotation speed on asymmetric oxidation/ reduction}

In our reaction, we found that when rotation speed was increased from 100 to $200 \mathrm{rpm}$, both yields were increased (Fig. 5d), indicating that mass transfer had a strong influence on the reaction process. Considering the oxidation step, the product yield showed little decrease when the rotation speed was above $250 \mathrm{rpm}$. However, in the reduction step, the product yield showed a big drop when rotation was increased to $300 \mathrm{rpm}$, reaching only 

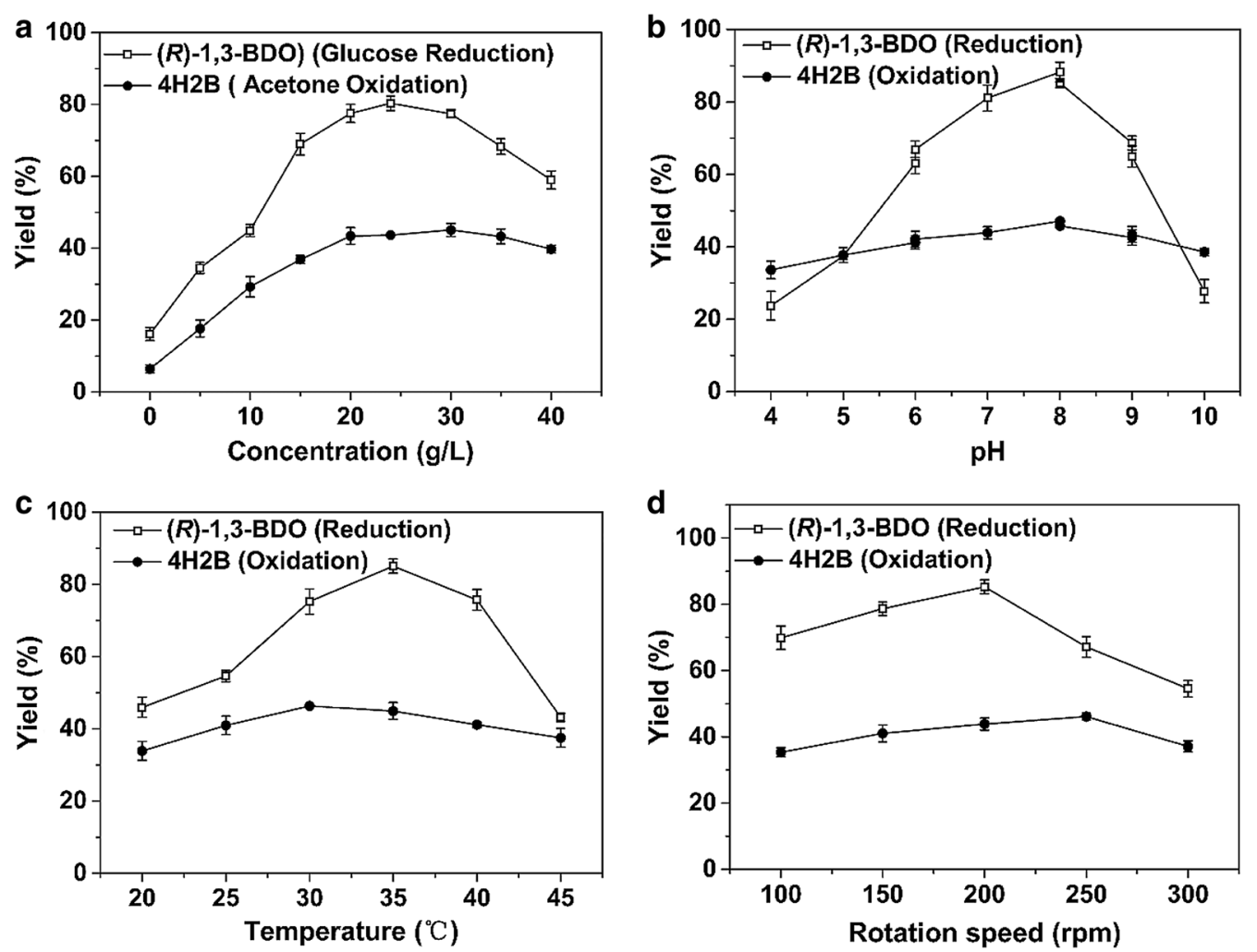

Fig. 5 Effects of reaction conditions on oxidation from the racemate to $4 \mathrm{H} 2 \mathrm{~B}$ and on the reduction from $4 \mathrm{H} 2 \mathrm{~B}$ to $(R)-1,3-\mathrm{BDO}$, respectively. a Effect of cosubstrate concentration on the asymmetric reaction, acetone used as the cosubstrate for oxidation from the racemate to $4 \mathrm{H} 2 \mathrm{~B}$ and glucose used as the cosubstrate for reduction from $4 \mathrm{H} 2 \mathrm{~B}$ to $(R)-1,3-\mathrm{BDO} ; \mathbf{b}$ effect of $\mathrm{pH}$ on the asymmetric oxidation and reduction, respectively; $\mathbf{c}$ effect of temperature on the asymmetric oxidation and reduction, respectively; $\mathbf{d}$ effect of rotation speed on the asymmetric oxidation and reduction, respectively

$54.51 \%$. Finally, the optimal rotation speed for the oxidation reaction was $250 \mathrm{rpm}$, while for the reduction reaction it was $200 \mathrm{rpm}$.

\section{Preparative scale cascade bioconversion of racemate to $(R)-1,3-\mathrm{BDO}$}

For constructing the stereoinverting cascade system, the conversion efficiency of the step-by-step approach was investigated, with one-pot method as a natural extension of the step-by-step experiment for performing the oxidation-reduction cascade. As shown in Fig. 6a, after a 48-h reaction, through the step-by-step approach we obtained $8.8 \mathrm{~g} / \mathrm{L}$ of $(R)-1,3-\mathrm{BDO}$ with $88 \%$ yield, and the ee of $(R)-1,3-\mathrm{BDO}$ was improved to $96.7 \%$. However, when using the second approach (one-pot reaction) (Fig. 6b), the concentrations of $(R)-1,3-\mathrm{BDO}$ and (S)-1,3-BDO remained almost constant, the ee of $(R)-1,3-$ BDO was close to zero, and this process therefore failed to complete deracemization. These results showed that there is a difference between the optimal oxidation and reduction conditions. In addition, the two strains also affect each other throughout the catalytic reaction in the one-pot system. Therefore, the step-by-step approach was adopted for this cascade process. C. parapsilosis QC-76 was firstly added to catalyze the oxidation reaction with acetone as the cosubstrate, then the cells were removed by centrifugation after the oxidation reaction $((S)-1,3-$ BDO in the racemic substrate was converted to the intermediate 4H2B); subsequently $P$. kudriavzevii QC-1 was added to catalyze the reduction reaction with glucose as the cosubstrate (the intermediate $4 \mathrm{H} 2 \mathrm{~B}$ was converted to $(R)-1,3-\mathrm{BDO})$.

According to the optimal condition results (cosubstrate, $\mathrm{pH}$, temperature, and rotation speed) previously obtained, the reaction system was scaled up to a $200-\mathrm{mL}$ working volume in a $500-\mathrm{mL}$ reactor. Since the optimum $\mathrm{pH}$ was the same for the oxidation and the reduction steps ( $\mathrm{pH} 8.0)$, the $\mathrm{pH}$ was maintained at 8.0 by the addition of $1 \mathrm{M}$ sodium hydroxide during the reaction. As shown in Fig. 6c, 10 g/L of (S)-1,3-BDO (20 g/L racemate substrate) were converted into $8.75 \mathrm{~g} / \mathrm{L}$ of $4 \mathrm{H} 2 \mathrm{~B}$ by $C$. parapsilosis QC-76 after a 48-h reaction; subsequently, C. parapsilosis $\mathrm{QC}-76$ cells were removed and P. kudriavzevii $\mathrm{QC}-1$ cells were added to the reaction, and $4 \mathrm{H} 2 \mathrm{~B}$ 

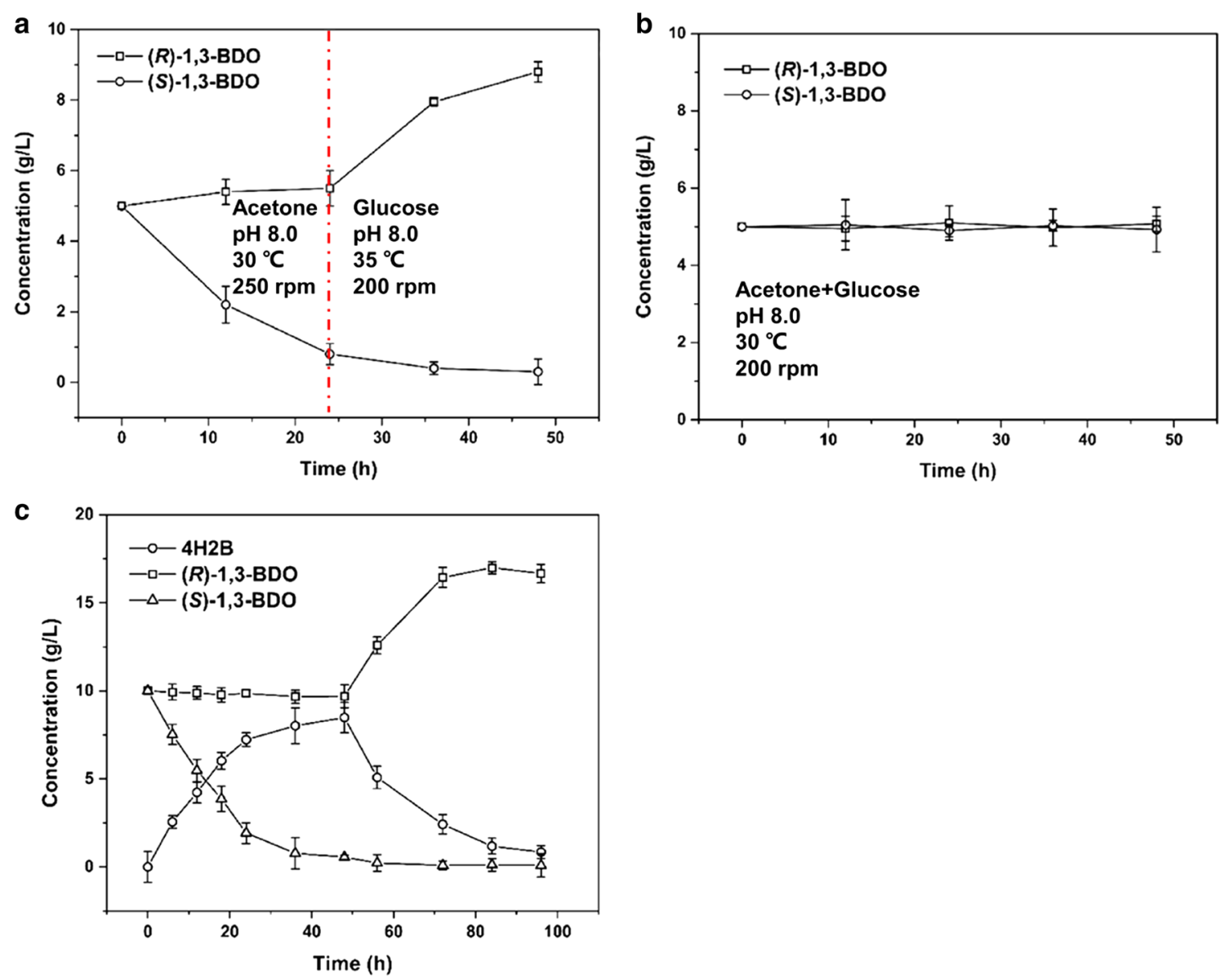

Fig. 6 Comparison of catalytic processes and scale-up of reaction system. a Step-by-step catalysis for the deracemization; $\mathbf{b}$ one-pot catalysis for the deracemization; c conversion of racemate to $(R)-1,3-\mathrm{BDO}$ in a $500-\mathrm{mL}$ bioreactor

was transformed into $(R)-1,3-\mathrm{BDO}$ with the final process yield $83.35 \%$ and a $99.5 \%$ ee.

\section{Discussion}

Stereoinversion-based deracemization is an important reaction route for asymmetric synthesis of various optically pure compounds, especially chiral pharmaceutical intermediates. Combination of suitable biocatalysts with desired stereospecificity and compatible catalytic properties provides a favorable alternative for constructing cascade biosystem catalyzing stereoinversion-based deracemization. However, screening biocatalysts with extremely high stereoselectivity and constructing a facile and efficient deracemization pathway are often the main challenges in the development of the required biological processes [9]. In this study, 544 colonies were isolated from the soil samples mostly collected from the regions close to pharmaceutical and chemical plants, which provide a high possibility of obtaining desired functional microorganisms performing activity towards relevant chemical compounds. By simultaneously evaluating the activity and stereoselectivity of candidate strains towards $4 \mathrm{H} 2 \mathrm{~B}$ or racemic 1,3-BDO, the strains QC-76 and QC-1 with the high conversion rate and stereospecificity $(>99 \%$ $e e)$ were screened for the oxidation and reduction reaction, respectively. It is worth to note that the obtained strains exhibited higher stereospecificity towards their corresponding reactions, than most of the previously reported stereospecific whole-cell biocatalysts, such as C. parapsilosis IFO 1396 (95\% ee), Geotrichum candidum (95\% ee), C. intermedia IFO 0761 (76\% ee), Kluyveromyces lactis IFO 1267 (93\% ee), C. utilis IAM 4277 (95\% ee), and Hansenula polymorpha ATCC 26012 (85\% ee) [15, 25]. In addition, these two strains were compatible for constructing a whole-cell stereoinverting cascade system. Through the cascade biocatalysis, the optical purity of the product $(R)-1,3-\mathrm{BDO}$ could be achieved over $99 \%$. Based on the taxonomical identification involving microbial morphology and sequence of 5.8S-ITS rDNA region, the strain QC-76 was identified as C. parapsilosis QC-76, 
and the strain QC-1 was identified as P. kudriavzevii QC-1. Of the two functional microorganisms, P. kudriavzevii $\mathrm{QC}-1$ was a novel strain discovered from natural source for catalyzing stereoselective reaction.

In order to further increase the bioconversion efficiency, we investigated the effects of reaction components on the yield and optical purity of the objective product. For stereoselective redox reaction, deficiency of necessary cofactor and its regeneration generally leads to a low substrate concentration or a low conversion efficiency [26]. To facilitate cofactor regeneration, various cosubstrates have been employed for recycling cofactors, with largely varied effects in terms of product yield and $e e[27,28]$. For the first step of oxidation, compared with other cosubstrates, such as glucose $(75.05 \% e e)$, fructose $(61.84 \% e e)$, and isopropanol $(41.28 \% e e)$, acetone was more favorable for giving the optical purity of $97.79 \% e e$. In the reaction, the added acetone promoted the complete and stereospecific conversion from $(S)-1,3-\mathrm{BDO}$ in the racemic substrate to $4 \mathrm{H} 2 \mathrm{~B}$ by C. parapsilosis QC-67 with the yield close to $50 \%$. Therefore, $(S)-1,3-\mathrm{BDO}$ in the racemic substrate was specifically oxidized to the intermediate $4 \mathrm{H} 2 \mathrm{~B}$ while $(R)-1,3-\mathrm{BDO}$ was retained during the deracemization process, which is essential to improve the optical purity of the final $(R)-1,3-\mathrm{BDO}(>99 \% e e)$ and enables the construction of a deracemization reaction route to meet the requirements of producing chiral building block with high optical purity. For the second step of reduction, glucose was selected as the suitable cosubstrate, providing reducing hydrogen to the conversion of oxidized cofactor into the corresponding reduced form and favoring the asymmetric reduction from the intermediate $4 \mathrm{H} 2 \mathrm{~B}$ to the final product $(R)-1,3-\mathrm{BDO}$.

In the process of microbial cells-mediated stereoselective transformation, temperature and $\mathrm{pH}$ are also important influencing factors for reactions. Change of temperature directly affects cell stability and enzyme activity, leading to changes of reaction rate and equilibrium [29]; switch of $\mathrm{pH}$ value of reaction system influences not only cell activity and dissociation state of functional groups in enzyme active site, but also the cofactor-involved electron transfer system [29, 30]. By optimization of these reaction conditions, the optimum temperatures for the first oxidation and the second reduction were determined as $30{ }^{\circ} \mathrm{C}$ and $35{ }^{\circ} \mathrm{C}$, respectively; the optimum $\mathrm{pH}$ value for both oxidation and reduction steps was determined as $\mathrm{pH} 8.0$, indicating the catalytic compatibility of the two whole-cell biocatalysts. In addition, rotation speed of a reaction vessel affects diffusion and mass transfer of the substrate and product during catalytic reactions [31]. The optimal rotation speed for the oxidation reaction was $250 \mathrm{rpm}$, while for the reduction reaction it was $200 \mathrm{rpm}$. It was presumed that the excessively fast rotation speed increased the availability of dissolved oxygen in the reaction solution, resulting in a negative influence on the reduction reaction [32]. By investigating the effects of various reaction conditions on each single-step conversion, we not only obtained the optimized conditions for conducting the oxidation-reduction cascade, but also understood the compatibility between C. parapsilosis QC-76-catalyzed oxidation and P. kudriavzevii QC-1-catalyzed reduction for further construction of suitable cascade system.

In this work, for constructing the stereoinverting cascade system, the feasibility of the step-by-step approach was investigated, with one-pot method as a natural extension of the step-by-step experiment for performing the oxidation-reduction cascade. Consequently, the stepby-step approach was adopted for this cascade process to avoid the mutual influence between the two microorganisms on the stereoinverting conversion. To facilitate the stereoinverting cascade reaction by the two wholecell biocatalysts, the cells of C. parapsilosis QC-67 were removed after the first oxidation step to prevent the negative effects of this strain on the second reduction step of 4H2B to $(R)-1,3-\mathrm{BDO}$ initiated by adding $P$. kudriavzevii QC-1 cells, while isolation of the intermediate $4 \mathrm{H} 2 \mathrm{~B}$ and change of reaction buffer were avoided, which minimized the loss of necessary reaction components, especially the substrate, the intermediate, and the product, and made the operation process more feasible and easier. Taken together, two whole-cell biocatalysts, $C$. parasilosis QC-76 and P. kudriavzevii QC-1, were characterized and used in the deracemization cascade synthesis of $(R)$ 1,3-BDO. After optimizing reaction conditions, $20 \mathrm{~g} / \mathrm{L}$ racemate was converted into $16.67 \mathrm{~g} / \mathrm{L}(R)-1,3-\mathrm{BDO}$ in a $200-\mathrm{mL}$ reaction with absolute enantioselectivity (>99\% $e e)$.

Concerning oxidation-reduction cascade, synthesis of other chiral alcohols, such as (R)-1-phenyl-1,2-ethanediol, has been reported to be achieved through stereoinversion-based deracemization by enzymatic catalysis [21]. For the coupled enzymes sequentially catalyzing cascade reaction, it would be necessary to keep the functional enzymes working in a compatible and synergistic way [21]. In this work, novel whole-cell biocatalysts were obtained to be capable of catalyzing stereoinverting cascade deracemization, producing $(R)-1,3-\mathrm{BDO}$ of high yield and optical purity. Based on the reaction route of cascade oxidation-reduction stereoinversion (Fig. 1), associating with the time courses of involved reactions (Fig. 4), we presumed that C. parapsilosis QC-76 would contain an $(S)$-specific dehydrogenase catalyzing selective oxidation from $(S)-1,3-\mathrm{BDO}$ to $4 \mathrm{H} 2 \mathrm{~B}$ and P. kudriavzevii $\mathrm{QC}-1$ would contain an $(R)$-specific carbonyl reductase catalyzing asymmetric reduction from $4 \mathrm{H} 2 \mathrm{~B}$ to 
(R)-1,3-BDO. The stereoselective oxidoreductases from the newly isolated strains will be further identified for constructing efficient enzymatic cascade system.

\section{Conclusions}

To the best of our knowledge, this is the first time that optically pure $(R)-1,3-\mathrm{BDO}$ was produced from the corresponding low-cost racemate by a cascade pathway with minimal substrate waste. Additionally, the proposed process is easy to operate since it relies on whole-cell biocatalysis and does not require isolation of intermediate. The deracemization cascade combining C. parapsilosis QC-76-mediated oxidation and P. kudriavzevii QC-1-mediated reduction provided high yield and stereochemical selectivity for $(R)-1,3-\mathrm{BDO}$ synthesis. Therefore, this work represents a discovery of novel whole-cell biocatalysts capable of performing stereoinversion in a facile and efficient manner, which shows much promise for further industrial applications.

\section{Methods \\ Chemicals}

Racemic 1,3-BDO, 4H2B, (R)-1,3-BDO and (S)-1,3-BDO were purchased from J\&K Scientific Co. (Beijing, China). All other medium components and chemical reagents were purchased from the Sinopharm Chemical Reagent Company (Shanghai, China).

\section{Analytical methods}

The optical purity of (R)-1,3-BDO was determined by HPLC using a Chiralcel OB-H column $(250 \mathrm{~mm} \times 4.6 \mathrm{~mm}$; Daicel Chemical Industries, Tokyo, Japan), with a mobile phase of hexane-isopropanol (19:1) at a flow rate of $1.0 \mathrm{~mL} / \mathrm{min}$. The column temperature was $40^{\circ} \mathrm{C}$, and we used a spectronic detector (ultraviolet, $\lambda=220 \mathrm{~nm}$. Shimazu, Kyoto, Japan) [25].

The (R)-1,3-BDO yield was determined by GCflame ionization using an Econo Cap-Wax column (30 $\mathrm{m} \times 250 \mu \mathrm{m} \times 0.25 \mu \mathrm{m}$; Alltech, Chicago, USA) and $\mathrm{N}_{2}$ as the carrier gas at a flow rate of $40 \mathrm{~mL} / \mathrm{min}$. The inlet and detector temperatures were $230{ }^{\circ} \mathrm{C}$ and $220{ }^{\circ} \mathrm{C}$ respectively, the column temperature was $225^{\circ} \mathrm{C}$, and the injection volume was $0.5 \mu \mathrm{L}$ [33].

\section{Screening and cultivation}

The medium used for cultivating isolated strains contained the following components: $2.0 \mathrm{~g} / \mathrm{L}\left(\mathrm{NH}_{4}\right)_{2} \mathrm{SO}_{4}$, $1.0 \mathrm{~g} / \mathrm{L} \mathrm{KH}_{2} \mathrm{PO}_{4}, 5.0 \mathrm{~g} / \mathrm{L}$ yeast extract, $10.0 \mathrm{~g} / \mathrm{L}$ tryptone, and $10.0 \mathrm{~g} / \mathrm{L}$ glucose (pH 7.0; solid medium also received $20.0 \mathrm{~g} / \mathrm{L}$ agar) [25].

More than 100 soil samples were mostly collected from the regions close to pharmaceutical factories and chemical plants, etc. Soil as a source of microbial strains was diluted with sterile water at $1: 100(\mathrm{w} / \mathrm{v})$, coated on screening plate medium and incubated at $30{ }^{\circ} \mathrm{C}$ for $24 \mathrm{~h}$. Single colonies were then picked, incubated in a 48 -well plate with cultivating medium, and cultured at $30{ }^{\circ} \mathrm{C}$ for $48 \mathrm{~h}$ [34]. These cultures were centrifuged at $7000 \times g$ for $10 \mathrm{~min}$, and $10 \mathrm{~g} / \mathrm{L} 4 \mathrm{H} 2 \mathrm{~B}$ or racemic $1,3-\mathrm{BDO}$ were then added to each well. The reaction was then carried out at $30{ }^{\circ} \mathrm{C}$ and $200 \mathrm{rpm}$ for $48 \mathrm{~h}$. The resulting cultures were centrifuged at $18,514 \times g$ for $5 \mathrm{~min}$, the supernatant was obtained, saturated with sodium chloride and then extracted with 2 volumes of ethyl acetate for $10 \mathrm{~min}$. The extracts were divided into two parts: one was dried using anhydrous $\mathrm{Na}_{2} \mathrm{SO}_{4}$ for gas chromatography (GC) analyses [33], and the other had the ethyl acetate removed by nitrogen blowing and acetylation with acetyl chloride in an ice bath for $10 \mathrm{~min}$, followed by resuspension of the reaction mixture in 2-propanol for optical purity analysis by high-performance liquid chromatography (HPLC) [25].

Yeast extract-peptone-dextrose (YPD) medium was used for cultivating strains QC-76 and QC-1, containing $5.0 \mathrm{~g} / \mathrm{L}$ yeast extract, $10.0 \mathrm{~g} / \mathrm{L}$ tryptone, and $10.0 \mathrm{~g} / \mathrm{L}$ glucose ( $\mathrm{pH} 7.0$; solid medium received $20.0 \mathrm{~g} / \mathrm{L}$ agar). The strains were cultivated at $30{ }^{\circ} \mathrm{C}$ with $200 \mathrm{rpm}$ shaking for $48 \mathrm{~h}$. Cells were collected, washed with a $0.9 \%$ sodium chloride solution, and used directly for biotransformation.

\section{Identification of microorganisms}

The morphologies of strains QC-76 and QC-1 were observed by scanning electron microscopy (SU8220; Hitachi, Tokyo, Japan) after growth on YPD agar for 2 days.

The isolated strains were taxonomically identified by sequencing the $5.8 \mathrm{~S}$-ITS rDNA region. We amplified these sequences with primers pITS1 (5'-TCCGTA GGTGAACCTGCCG-3') and pITS4 (5'-TCCTCC GCTTATTGATATGC-3') [35]. The obtained 5.8S-ITS regions were determined and aligned with the reference sequences retrieved from the GenBank database Clustal W [36]. Related sequences were obtained from the GenBank database using the Basic Local Alignment Search Tool (BLAST). The Molecular Evolutionary Genetics Analysis (MEGA) 6 software v. 6.0 was applied for the calculation of evolutionary distances, and a phylogenetic tree was constructed using the neighbor-joining method [37].

\section{Verification of each single-step reaction by functional strain}

The verification experiments included the $C$. parapsilosis QC-76-catalyzed oxidation reaction and the P. kudriavzevii $\mathrm{QC}-1$-catalyzed reduction reaction. According 
to previous reports and pre-tests [38, 39], we evaluated the effect of several cosubstrates, such as acetophenone, fructose, glucose, galactose, acetone, isopropanol, 2-pentanone, and glycerol in the oxidation step; for the reduction step, we evaluated glucose, 1-butanol, glycerol, xylan, and ethanol. The conditions for the oxidation reaction included $20 \mathrm{~g} / \mathrm{L}$ of racemate, $1.5 \mathrm{~g}$ of wet strain QC-76, $10 \mathrm{~g} / \mathrm{L}$ of acetone, $30{ }^{\circ} \mathrm{C}, 200 \mathrm{rpm}, \mathrm{pH}$ 7.0; regarding the reduction reaction, conditions included $20 \mathrm{~g} / \mathrm{L}$ of $4 \mathrm{H} 2 \mathrm{~B}, 1.5 \mathrm{~g}$ of wet strain QC-1, $20 \mathrm{~g} / \mathrm{L}$ of glucose, $30^{\circ} \mathrm{C}$, $200 \mathrm{rpm}$, and $\mathrm{pH}$ 7.0. All experiments were carried out in $10-\mathrm{mL}$ reaction systems, and the contents of $4 \mathrm{H} 2 \mathrm{~B},(R)-$ 1,3-BDO, and (S)-1,3-BDO were detected throughout the reactions.

\section{Optimization of single-step reaction conditions}

Cosubstrates, $\mathrm{pH}$, temperature, and rotation speed were optimized separately for the oxidation and reduction reactions. The temperature range was $20-45{ }^{\circ} \mathrm{C}$, with $5{ }^{\circ} \mathrm{C}$ intervals; the $\mathrm{pH}$ range was $4.0-10.0$, with $\mathrm{pH} 1.0$ intervals; the rotation speed range was 100-300 rpm, with 50-rpm intervals.

\section{Stereoinverting cascade for deracemization of 1,3-BDO to $(R)-1,3-\mathrm{BDO}$}

Two approaches for performing the oxidation-reduction cascade in the $10-\mathrm{mL}$ reaction system were conducted. In the first approach (step-by-step manner), $2 \mathrm{~g}$ of wet strain QC-76 was used to conduct the first oxidation reaction with acetone as the cosubstrate under $\mathrm{pH} 8.0$ at $30{ }^{\circ} \mathrm{C}$ and $250 \mathrm{rpm}$ for $24 \mathrm{~h}$, then the strain was discarded, and finally the second step was conducted by adding $2 \mathrm{~g}$ of wet strain QC-1 with glucose as the cosubstrate under $\mathrm{pH} 8.0$ at $35{ }^{\circ} \mathrm{C}$ and $200 \mathrm{rpm}$ for $24 \mathrm{~h}$. In the second approach (one-pot reaction), $2 \mathrm{~g}$ of wet strains QC-76 and QC-1 were simultaneously added into the one-pot reaction system comprising racemic substrate, acetone, and glucose under $\mathrm{pH} 8.0$ at $30{ }^{\circ} \mathrm{C}$ and $200 \mathrm{rpm}$ in order to perform the oxidation-reduction cascade reaction at the same time. According to the obtained results, the cascade reactions were scaled up to a $500-\mathrm{mL}$ bioreactor (EnzyR $500 \mathrm{~mL}$; T\&J, Shanghai, China) with $200 \mathrm{~mL}$ working volume. First, $20 \mathrm{~g} / \mathrm{L}$ of the racemate and $35 \mathrm{~g}$ of wet strain QC-76 were added to the reaction, and $\mathrm{pH}$ was maintained at 8.0 with $1 \mathrm{M}$ sodium hydroxide. The concentrations of 4H2B, $(R)-1,3-\mathrm{BDO}$, and $(S)-1,3-\mathrm{BDO}$ were detected during the conversion process. When the (S)-1,3-BDO was mostly transformed into 4H2B, the QC-76 cells were discarded by centrifugation, and $35 \mathrm{~g}$ of wet strain QC-1 and the glucose were then added for the transformation from $4 \mathrm{H} 2 \mathrm{~B}$ to $(R)-1,3-\mathrm{BDO}$.

\section{Abbreviations}

ee: Enantiomeric excess; 1,3-BDO: 1,3-Butanediol; 4H2B: 4-Hydroxy-2-butanone; ITS: Internal transcribed spacer; GC: Gas chromatography; HPLC: Highperformance liquid chromatography; YPD: Yeast extract-peptone-dextrose; BLAST: Basic Local Alignment Search Tool; MEGA: Molecular Evolutionary Genetics Analysis.

\section{Acknowledgements}

We would like to thank Editage (http://www.editage.cn) for English language editing.

\section{Authors' contributions}

$\mathrm{HZ}$ and $\mathrm{YN}$ designed the experiments. $\mathrm{HZ}$ led the performance of the experiments, analysis of the data and writing of the paper. JG, $\mathrm{HZ}$, and AF participated in experiments and analysis. $H Z, Y N$ and $Y X$ participated in editing the paper. All authors read and approved the final manuscript.

\section{Funding}

This work was supported by the National Natural Science Foundation of China (NSFC) (Grant 21676120, 31872891), the 111 Project (Grant 111-2-06), the High-end Foreign Experts Recruitment Program (Grant G20190010083), the Program for Advanced Talents within Six Industries of Jiangsu Province (Grant 2015-NY-007), the National Program for Support of Top-notch Young Professionals, the Fundamental Research Funds for the Central Universities (Grant JUSRP51504), the Project Funded by the Priority Academic Program Development of Jiangsu Higher Education Institutions, Top-notch Academic Programs Project of Jiangsu Higher Education Institutions, the Jiangsu Province "Collaborative Innovation Center for Advanced Industrial Fermentation" Industry Development Program, the Program for the Key Laboratory of Enzymes of Suqian (M201803), and the National First-Class Discipline Program of Light Industry Technology and Engineering (Grant LITE2018-09).

\section{Availability of data and materials}

We declared that materials described in the manuscript, including all relevant raw data, will be freely available to any scientist wishing to use them for noncommercial purposes, without breaching participant confidentiality.

\section{Ethics approval and consent to participate}

This article does not contain any studies with human participants or animals performed by any of the authors.

\section{Consent for publication}

Not applicable.

\section{Competing interests}

The authors declare that they have no competing interests.

\section{Author details \\ ${ }^{1}$ Key Laboratory of Industrial Biotechnology, Ministry of Education, School of Biotechnology, Jiangnan University, 1800 Lihu Road, Wuxi 214122, China. 2 State Key Laboratory of Food Science and Technology, Jiangnan University, 1800 Lihu Road, Wuxi 214122, China. ${ }^{3}$ Suqian Industrial Technology Research Institute of Jiangnan University, Suqian 223814, China.}

Received: 25 February 2020 Accepted: 30 May 2020

Published online: 08 June 2020

\section{References}

1. Patel RN. Biocatalytic synthesis of chiral alcohols and amino acids for development of pharmaceuticals. Biomolecules. 2013;3:741-77.

2. Kataoka M, Kita K, Wada M, Yasohara Y, Hasegawa J, Shimizu S. Novel bioreduction system for the production of chiral alcohols. Appl Microbiol Biotechnol. 2003;62:437-45.

3. Woodley JM. New opportunities for biocatalysis: making pharmaceutical processes greener. Trends Biotechnol. 2008;26:321-7.

4. Matsuda T, Yamanaka R, Nakamura K. Recent progress in biocatalysis for asymmetric oxidation and reduction. Tetrahedron Asymmetry. 2009;20:513-57. 
5. Boaz NW, Ponasik JA, Large SE. Ruthenium complexes of phosphineaminophosphine ligands. Tetrahedron Lett. 2006;47:4033-5.

6. Yasuo T, Hiroaki U, Hiroshi K. High-purity 1,3-butylene glycol, process for producing 1,3-butylene glycol, and process for producing by-product butanol and butyl acetate. PAT:WO0156963; Japan patent; 2001.

7. Iwata H, Tanaka R, Ishiguro M. Structures of the alkaline hydrolysis products of penem antibiotic, SUN5555. J Antibiot. 1990;43:901-3.

8. Llarrull LI, Testero SA, Fisher JF, Mobashery S. The future of the $\beta$-lactams. Curr Opin Microbiol. 2010;13:551-7.

9. Zheng RC, Ge Z, Qiu ZK, Wang YS, Zheng YG. Asymmetric synthesis of (R)-1,3-butanediol from 4-hydroxy-2-butanone by a newly isolated strain Candida krusei ZJB-09162. Appl Microbiol Biotechnol. 2012;94:969-76.

10. Kroutil W, Mang H, Edegger K, Faber K. Recent advances in the biocataIytic reduction of ketones and oxidation of sec-alcohols. Curr Opin Chem Biol. 2004;8:120-6.

11. Nakamura K, Yamanaka R, Matsuda T, Harada T. Recent developments in asymmetric reduction of ketones with biocatalysts. Tetrahedron Asymmetry. 2003;14:2659-81.

12. Schmid A, Dordick JS, Hauer B, Kiener A, Wubbolts M, Witholt B. Industrial biocatalysis today and tomorrow. Nature. 2001:409:258-68.

13. Matsuyama A, Yamamoto H, Kawada N, Kobayashi Y. Industrial production of (R)-1,3-butanediol by new biocatalysts. J Mol Catal B Enzym. 2001;11:513-21.

14. Kataoka N, Vangnai AS, Tajima T, Nakashimada Y, Kato J. Improvement of (R)-1,3-butanediol production by engineered Escherichia coli. J Biosci Bioeng. 2013;115:475-80

15. Matsuyama A, Kobayashi Y, Ohnishi H. Microbial production of optically active 1,3-butanediol from the racemate. Biosci Biotechnol Biochem. 1993;57:685-6.

16. Nakamura K, Fujii M, Ida Y. Stereoinversion of arylethanols by Geotrichum candidum. Tetrahedron Asymmetry. 2001:12:3147-53.

17. Hwang ET, Lee S. Multienzymatic cascade reactions via enzyme complex by immobilization. ACS Catal. 2019;9:4402-25.

18. Farnberger JE, Lorenz E, Richter N, Wendisch VF, Kroutil W. In vivo plugand-play: a modular multi-enzyme single-cell catalyst for the asymmetric amination of ketoacids and ketones. Microb Cell Fact. 2017:16:1-17.

19. Du PX, Wei P, Lou WY, Zong MH. Biocatalytic anti-Prelog reduction of prochiral ketones with whole cells of Acetobacter pasteurianus GIM1.158. Microb Cell Fact. 2014;13:1-9.

20. Schrittwieser JH, Sattler J, Resch V, Mutti FG, Kroutil W. Recent biocatalytic oxidation-reduction cascades. Curr Opin Chem Biol. 2011;15:249-56.

21. Li B, Nie Y, Mu XQ, XuY. De novo construction of multi-enzyme system for one-pot deracemization of (R, S)-1-phenyl-1,2-ethanediol by stereoinversion of (S)-enantiomer to the corresponding counterpart. J Mol Catal - B Enzym. 2016;129:21-8.

22. Schrittwieser JH, Groenendaal B, Resch V, Ghislieri D, Wallner S, Fischereder EM, et al. Deracemization by simultaneous bio-oxidative kinetic resolution and stereoinversion. Angew Chem Int Ed. 2014;53:3731-4.

23. Xie $\mathrm{Y}, \mathrm{Xu} \mathrm{JH}, \mathrm{Xu}$ Y. Isolation of a Bacillus strain producing ketone reductase with high substrate tolerance. Bioresour Technol. 2010;101:1054-9.

24. Doneva T, Vassilieff C, Donev R. Catalytic and biocatalytic oxidation of glucose to gluconic acid in a modified three-phase reactor. Biotechnol Lett. 1999:21:1107-11.

25. Matsuyama A, Kobayashi Y, Ohnishi H. Microbial production of optically active 1, 3-butanediol from 4-Hydroxy-2-butanone. Biosci Biotechnol Biochem. 1993;57:348-9.
26. Stewart JD. Organic transformations catalyzed by engineered yeast cells and related systems. Curr Opin Biotechnol. 2000;11:363-8.

27. Quezada MA, Carballeira JD, Sinisterra JV. Monascus kaoliang CBS 302.78 immobilized in polyurethane foam using iso-propanol as co-substrate: optimized immobilization conditions of a fungus as biocatalyst for the reduction of ketones. Bioresour Technol. 2009;100:2018-25.

28. Wolfson A, Dlugy C, Tavor D, Blumenfeld J, Shotland Y. Baker's yeast catalyzed asymmetric reduction in glycerol. Tetrahedron Asymmetry. 2006:17:2043-5.

29. Guo JL, Mu XQ, Xu Y. Integration of newly isolated biocatalyst and resinbased in situ product removal technique for the asymmetric synthesis of (R)-methyl mandelate. Bioprocess Biosyst Eng. 2010;33:797-804

30. Katz M, Sarvary I, Frejd T, Hahn Hägerdal B, Gorwa Grauslund MF. An improved stereoselective reduction of a bicyclic diketone by Saccharomyces cerevisiae combining process optimization and strain engineering. Appl Microbiol Biotechnol. 2002:59:641-8.

31. Wang P, Cai JB, Ouyang Q, He JY, Su HZ. Asymmetric biocatalytic reduction of 3,5-bis(trifluoromethyl) acetophenone to (1R)-[3,5bis(trifluoromethyl)phenyl] ethanol using whole cells of newly isolated Leifsonia xyli HS0904. Appl Microbiol Biotechnol. 2011:90:1897-904.

32. Ma F, Sun Y, Li A, Zhang X, Yang J. Activation of accumulated nitrite reduction by immobilized Pseudomonas stutzeriT13 during aerobic denitrification. Bioresour Technol. 2015;187:30-6.

33. Yang T, Man Z, Rao Z, Xu M, Zhang X, Xu Z. Asymmetric reduction of 4-hydroxy-2-butanone to (R)-1,3-butanediol with absolute stereochemical selectivity by a newly isolated strain of Pichia jadinii. J Ind Microbiol Biotechnol. 2014:41:1743-52.

34. Hena S, Abida N, Tabassum S. Screening of facultative strains of high lipid producing microalgae for treating surfactant mediated municipal wastewater. RSC Adv. 2015;5:98805-13.

35. White TJ, Bruns T, Lee S, Taylor J. Amplification and direct sequencing of fungal ribosomal RNA genes for phylogenetics. In: Innis MA, Gelfand $\mathrm{DH}$, Sninsky JJ, White TJ, editors. PCR protocols: a guide to methods and applications. New York: Academic Press; 1990. p. 315-22.

36. Thompson JD, Higgins DG, Gibson TJ. CLUSTAL W (improving the sensitivity of progressive multiple sequence alignment through sequence weighting, position-specific gap penalties and weight matrix choice). Nucleic Acids Res. 1994:22:4673-80.

37. Tamura K, Stecher G, Peterson D, Filipski A, Kumar S. MEGA6: molecular evolutionary genetics analysis version 6.0. Mol Biol Evol. 2013;30:2725-9.

38. Fieser LF, Fieser M, Ho T, Ho T, Fieser M, Fieser L. Synthesis of (R)-1,3-butanediol by enantioselective oxidation using whole recombinant Escherichia coli cells expressing (S)-specific secondary alcohol dehydrogenase. Biosci Biotechnol Biochem. 2002;66:925-7.

39. Matsuyama A, Kobayashi Y. Large-scale preparation of (R)-(-)-1,3-butanediol from the Racemate by Candida parapsilosis. Biosci Biotechnol Biochem. 1994:58:1148-9.

\section{Publisher's Note}

Springer Nature remains neutral with regard to jurisdictional claims in published maps and institutional affiliations.

Ready to submit your research? Choose BMC and benefit from:

- fast, convenient online submission

- thorough peer review by experienced researchers in your field

- rapid publication on acceptance

- support for research data, including large and complex data types

- gold Open Access which fosters wider collaboration and increased citations

- maximum visibility for your research: over 100M website views per year

At BMC, research is always in progress.

Learn more biomedcentral.com/submissions 